\title{
DISPUTAS CURRICULARES EM TORNO DA FORMAÇÃO INICIAL E CONTINUADA NO BRASIL: anunciações políticas das entidades científicas
}

\author{
Ana Cláudia da Silva Rodrigues \\ Universidade Federal da Paraíba - UFPB, Brasil \\ Ângela Cristina Alves Albino \\ Universidade Federal da Paraíba - UFPB, Brasil
}

Rafael Ferreira de Souza Honorato

Universidade Federal da Paraíba - UFPB, Brasil

\begin{abstract}
Resumo
Este estudo documental e bibliográfico traz um recorte histórico de manifestos veiculados pelas entidades científicas acerca da produção das políticas curriculares de formação docente. Analisa o movimento que antecede a Resolução 02/2019, que definiu as Diretrizes Curriculares Nacionais para a Formação Inicial de Professores para a Educação Básica e instituiu a Base Nacional Comum para a Formação Inicial de Professores da Educação Básica (BNC-Formação). Destaca, no final, o Manifesto de maio de 2020 da ANPED e das entidades signatárias em que repudiam a Resolução $\mathrm{CNE} / \mathrm{CP} \mathrm{n}^{\circ}$ 1, de 27/10/2020, referente às Diretrizes Curriculares Nacionais para a Formação Continuada de Professores da Educação Básica e que instituiu a BNC - Formação Continuada. São abordadas algumas dimensões da formação em meio à crise política, sanitária e econômica e põe em evidência o posicionamento político das entidades em relação aos processos de formulação das resoluções de formação bem como, o que rejeitam como modelo formativo.
\end{abstract}

Palavras-chave: Formação; Políticas; Entidades científicas.

\begin{abstract}
This documental and bibliographical study brings a historical outline of manifests conveyed by scientific entities about the production of curriculum policies for teacher education. It analyzes the movement that precedes Resolution 02/2019, which defined the National Curriculum Guidelines for Initial Teacher Training for Basic Education and instituted the Common National Base for Initial Basic Education Teacher Training (BNC-Training). At the end, it highlights the Manifesto of May 2020 by ANPED and the signatory entities in which they repudiate Resolution CNE/CP No. 1, of $10 / 27 / 2020$, referring to the National Curriculum Guidelines for the Continuing Training of Teachers in Basic and which created the BNC - Formation Continuing. Some dimensions of training in the midst of the political, health and economic crisis are addressed and it highlights the political position of the entities in relation to the processes of formulating training resolutions, as well as what they reject as a training model.
\end{abstract}

Keywords: Training; Policies; Scientific entities. 


\section{1 - À GUISA DE UM COMEÇO: ASPECTOS HISTÓRICOS PARA PENSAR NA DOCÊNCIA E A FORMAÇÃO NO BRASIL}

A formação docente, numa perspectiva histórica e curricular, encontra-se ancorada à princípio de: seleção, denúncia, controle, anunciação e transbordamento. No que diz respeito à responsabilidade pública, é pouco reconhecida politicamente para o desenvolvimento da nação brasileira. Ela nasce atrelada à expansão do sistema de ensino, mas carrega marcas do processo colonizador com o ideal de manter a ordem e o disciplinamento de condutas, coo se fazia na formação dos curumins.

No percurso histórico, um fato emblemático como o Decreto Imperial, de 15 de outubro de 1827, é bem ilustrativo do desenho formativo no Brasil. Embora seja um marco importante e referência para docentes, em termos de descentralização, ensino mútuo, currículo mínimo e admissão de professores, já previa um processo de formação às avessas, em que o docente deveria custear a própria formação. “Os professores que não tiverem a necessária instrução deste ensino (mútuo) irão instruir-se em curto prazo e à custa de seus ordenados, nas escolas das capitais" (BRASIL, 1827).

No Brasil, de modo geral, a compreensão da docência parece ainda ser eivada no dispositivo epistemológico-histórico do pedagogo: o escravo encarregado de oferecer formação (Paidéia) cultural e intelectual, adicionado das influências cristãs do messianismo da caridade e penitência permanente, por um pecado que sequer cometeu. A docência, sobretudo da educação básica, parece constituir-se na tensão entre "salvadora" das mazelas e, ao mesmo tempo, culpada por ser essa "entidade concreta/abstrata" profissional desprovida de técnicas e de rituais capazes de resolver os problemas de aprendizagem e, até mesmo, da evasão escolar do país.

As lutas por um projeto de formação seguem seu curso com dilemas e retrocessos, inclusive sem impulsionar a valorização profissional. $\mathrm{O}$ ordenamento político não é estável nem linear, pois se assim o fosse, bastaria fazer a atualização monetária do salário de um professor, em 1827, para saber que, atualmente, o valor é inferior.

No Brasil, a formação docente aparece como um descontinum histórico tenso e disputado. Assumimos a compreensão de Freire (2005) e de Arroyo (2012) de que é necessária uma formação humana que enseje movimento e rupturas necessárias ao projeto colonizador que continua em curso. A formação é parte de um projeto político que pressupõe relações de poder-saber que precisam ser repensadas, sobretudo nas práticas epistemicidas que violam a cultura e o lugar do outro nos processos de decisão curricular. O professor se faz e refaz em um espaço-tempo cultural e político de hierarquização de saberes e constrói seu percurso por meio de múltiplos saberes que transbordam dos processos de gerencialistas que se põem em curso pelos marcos regulatórios de uma política de formação engendradas na lógica racional tecnicista pautada em "evidências culturais internacionais" recorrentes na BNCC - Base Nacional Comum Curricular.

A docência, com seus processos formativos profissionais, é uma prática curricular que se recontextualiza. É um movimento e um "momento em que alunos e professores vivenciam 
experiências nas quais constroem e reconstroem conhecimentos e saberes" (MOREIRA, 1998, p. 22). Não compreendemos a política de formação docente descolada do currículo. Elas se imbricam nos modos de significar a vida e o cotidiano escolar, numa mistura heterogênea, politicopoética de dizer/fazer o mundo.

No percurso histórico que marca a atual efervescência de pensar no currículo de formação docente, as entidades científicas endereçam suas preocupações aos modos antidemocráticos como se constituem as diretrizes formativas. Convém lembrar o pensamento de Freire (2005, p.169) de que "a manipulação, na teoria de ação antidialógica, tal como a conquista a que serve, tem de anestesiar as massas populares para que não pensem". Ainda assim, os movimentos de atuação das entidades que se contrapõem às resoluções de formação chamam a comunidade científica, na clássica convocatória de Arroyo (2012, p. 43), para [...] ocupar os espaços, os territórios e as instituições, como escolas, universidades e 'latifúndios do saber' como uma pedagogia formadora que se contrapõe à histórica exclusão desses espaços, instituições de produção do conhecimento e da existência”.

Nesse ínterim, apresentaremos uma análise geral das políticas de formação, basicamente detendo-nos em três manifestos organizados pela Associação Nacional de Pós-Graduação e Pesquisa em Educação (ANPED), pela Associação Nacional pela Formação dos Profissionais da Educação (ANFOPE) e pelo Fórum Nacional dos Diretores de Faculdades e Centro de Educação (FORUMDIR) que se posicionaram contra os modelos de formação inicial e continuada entre 2018 e 2020. Quais as (de)anunciações políticas de formação docente? O que rejeitam em seus manifestos ou notas públicas?

O contexto neoconservador, com disputas intensas pelo modelo societário e de formação humana, enseja um modelo de conhecimento delimitado e encaixotado, a partir da lógica das competências e das habilidades constantes na Base Nacional Comum Curricular (BNCC 2018, 2018). No contexto pandêmico da covid-19, presenciamos um movimento intenso de aprovação e "passagem da boiada" de políticas curriculares de formação à revelia das entidades e dos pesquisadores da área educacional.

O avanço político da direita é outro fator a ser considerado no desenho das políticas curriculares do Brasil. Uma de suas formas é o que Duarte (2018, p. 139) chamou de obscurantismo beligerante, entendido como "a difusão de ataque ao conhecimento e à razão de cultivo de atitudes fortemente agressivas contra tudo aquilo que possa ser considerado ameaçador para posições ideológicas conservadoras e preconceituosas". Ele afirma que não é um fenômeno novo e que, em 1964, às vésperas do golpe, muitos setores da direita organizaram movimentos com feições obscurantistas e beligerantes intensificadas e favorecidas pelos ambientes virtuais.

O Conselho Pleno (CP) e a Câmara de Educação Básica (CEB) do Conselho Nacional de Educação aprovaram, em novembro de 2019, a Resolução que define as Diretrizes Curriculares Nacionais para a Formação Inicial de Professores para a Educação Básica e institui a Base Nacional Comum para a Formação Inicial de Professores da Educação Básica (BNC-Formação). Nesse ínterim, a Resolução 02/2019, ao revogar a Resolução 02/2015, descaracterizou e divididiu a formação inicial e continuada bem como aprofundou o vazio de enunciação de uma política de valorização do Magistério brasileiro. 


\section{2 - A RESOLUÇÃO CNE/CP 02/2015: ANTECEDENTES E PAUTAS PRINCIPAIS}

As Diretrizes Curriculares Nacionais para a Formação Inicial e Continuada em Nível Superior de Profissionais do Magistério para a Educação Básica foram definidas pelo Conselho Nacional de Educação (CNE), por meio da Resolução CNE/CP n 2 de 2015, em substituição às Diretrizes Curriculares Nacionais para a Formação de Professores da Educação Básica, em nível superior, curso de licenciatura e de graduação plena (DCNs), Resolução CNE/CP No 1, de 18 de fevereiro de 2002. Embora as DCNs/2002 passassem a requerer uma formação específica e de superação da clássica formação “ $3+1$ ”, que priorizava a formação específica em detrimento dos conteúdos pedagógicos, não atenderam às demandas das entidades de formação e dos educadores. Essas diretrizes fazem parte do projeto político do então presidente na época, Fernando Henrique Cardoso, que buscava viabilizar o processo de reestruturação produtiva rumo à "especialização flexível".

Para Freitas (2002), as diretrizes de 2002 imprimiram a marca do aligeiramento da formação, na perspectiva de centrar a formação em habilidades e competências, o que também foi reafirmado, a posteriori, por Aguiar \& Dourado (2019, p. 35), quando afirmaram que a formação docente é parte de um projeto político: “[...] a formação dos professores se sobressai, por ser um elemento estratégico para materializar a pretendida reforma atendendo aos reclamos do mercado, que pugna pela formação do sujeito produtivo e disciplinado". Enfim, os perfis ensejados nesse percurso histórico atendem aos gritos do mercado.

As DCNs de 2002 não se acomodaram tranquilamente nos contextos das práticas educativas. Essa constituição formativa enfrentou um processo de resistência na esfera política provocada pela mudança de governo com a eleição do Presidente Luís Inácio da Silva, bem como das entidades que defendiam outros princípios de formação, como a ANFOPE, por exemplo. Nessa reconfiguração política e de disputa de projetos educacionais, depois de uma década, foram aprovadas as novas diretrizes de formação docente, que, de certa forma, foram discutidas por meio de audiências regionais e nacionais configuradas como Resolução CNE/CP n ${ }^{\circ}$ 2/2015.

A Resolução 02/2015 contempla muitas das contribuições da ANFOPE, da ANPAE, da ANPED, do FORUMDIR e do Centro de Estudos, Educação e Sociedade (CEDES). Dentre elas, destaca-se a compreensão de base comum nacional, entendida como um amálgama de princípios, e não, como receituário de prescrição curricular. A docência é amplamente entendida como uma ação educativa de ensinar, assimilada às condições e às funções para sua realização, pesquisa e extensão como princípio pedagógico de articulação teórico-prática e de aprimoramento profissional. Trata-se da formação cultural e científica, mediada por múltiplas linguagens e tecnologias.

Para Dourado (2015), as deliberações das Conferências Nacionais de Educação (CONAES), em 2010 e 2014, cumpriram um importante papel ao defender a articulação entre o Sistema Nacional de Educação, as políticas e a valorização dos profissionais da Educação. $\mathrm{O}$ autor, membro da Câmara Superior do Conselho Nacional de Educação, no período de 
2012 a 2018, e durante a elaboração da Resolução 02/2015, participante da Comissão Bicameral do referido conselho, designada com o propósito de pensar a formação de professores, destaca que a aprovação do Plano Nacional de Educação pelo Congresso Nacional, através da Lei $n^{\circ} 13.005 / 2014$, responsável por estabelecer novos direcionamentos para as políticas educacionais brasileiras, foi um importante documento orientador das proposições das diretrizes. Enfatiza, ainda, que a diretriz aprovada em 2015 foi o resultado de um processo de construção na tentativa de considerar as diferentes concepções em disputas no campo e resultou do intuito de "garantir maior organicidade para a formação inicial e continuada dos profissionais para o magistério da educação básica" (p. 299).

Importante destacar que a aprovação da DCN 02/2015, depois de ampla discussão em audiências públicas, reuniões da Comissão Bicameral, estudos nacionais, contribuições de pesquisadores da área e entidades, norteou a elaboração dos princípios da formação inicial e continuada de profissionais do Magistério da educação básica. Tais definições foram responsáveis por indicar a necessidade de mais organicidade nos projetos formativos, de articulação entre as instituições de educação superior e as de educação básica e considerar a

I. Sólida formação teórica e interdisciplinar dos profissionais;

II. A inserção dos estudantes de licenciatura nas instituições de educação básica da rede pública de ensino, espaço privilegiado da práxis docente;

III. O contexto educacional da região onde será desenvolvido;

IV. Atividades de socialização e avaliação dos impactos;

V. Aspectos relacionados à ampliação e ao aperfeiçoamento do uso da língua portuguesa e à capacidade comunicativa, oral e escrita, como elementos fundamentais da formação dos professores e à aprendizagem de Libras;

VI. Questões socioambientais, éticas, estéticas e relativas à diversidade étnicoracial, de gênero, sexual, religiosa, de faixa geracional e sociocultural como princípios de equidade.

Compreendemos, a partir dos princípios elencados, que, depois de aprovado, o projeto de formação deveria ser institucionalizado em cada instituição formadora com a construção de uma identidade própria e se vincular aos direcionamentos do Plano de Desenvolvimento Institucional (PDI), do Projeto Pedagógico Institucional (PPI) e do Projeto Pedagógico de Curso (PPC). Para isso, foi estabelecido um prazo de dois anos.

Como vimos, mesmo de forma breve, as DCN 02/2015 são importantes e defendem uma concepção de docência imbricada no exercício articulado dos processos de ensino e aprendizagem, a gestão e a organização da educação básica. Porém, para que sejam consolidadas, o Estado deve garantir novos recursos, na tentativa de cumprir a meta de atingir a destinação de $10 \%$ do PIB para a Educação, acompanhar a atualização dos currículos nas instituições formativas e estabelecer um Sistema Nacional de Educação, como previsto no Plano Nacional de Educação (DOURADO, 2015).

Ressalte-se, no entanto, que, dez meses depois que as diretrizes foram aprovadas - em junho de 2015 - instaurou-se, no país, um período de instabilidade política que culminou com o afastamento da Presidente eleita, Dilma Roussef, e novos atores entraram em cena 
para redirecionar os rumos políticos, econômicos, sociais e educacionais do país. No Conselho Nacional de Educação, 11 dos seus membros tiveram suas nomeações revogadas pelo Presidente interino, Michel Temer, através de um decreto assinado em conjunto com o ministro da Educação, Mendonça Filho, o que se configurou como uma ação do governo relativa à revisão dos últimos atos assinados por Dilma Rousseff. Os conselheiros foram nomeados em 11 de maio, um dia antes da votação no Senado, que afastou a Presidente do cargo por 180 dias. Essa mudança não significou apenas uma substituição de representações de entidades como CONSED, APEOESP, UNDIME, ANDIFES e docentes vinculados a instituições públicas e privadas no país. Os novos conselheiros, conforme mostra a Figura 1, abaixo, representam interesses cuja maioria é dos organismos internacionais a que se vinculam e foram os responsáveis por instituir políticas educacionais, dentre elas, a elaboração e posterior aprovação das Diretrizes Curriculares Nacionais para a Formação Inicial de Professores para a Educação Básica, e a Base Nacional Comum para a Formação Inicial de Professores da Educação Básica (BNC-Formação), com um viés mercadológico e subordinada aos ditames neoliberais.

Figura 1- Configuração do Conselho Nacional de Educação 2016-2020

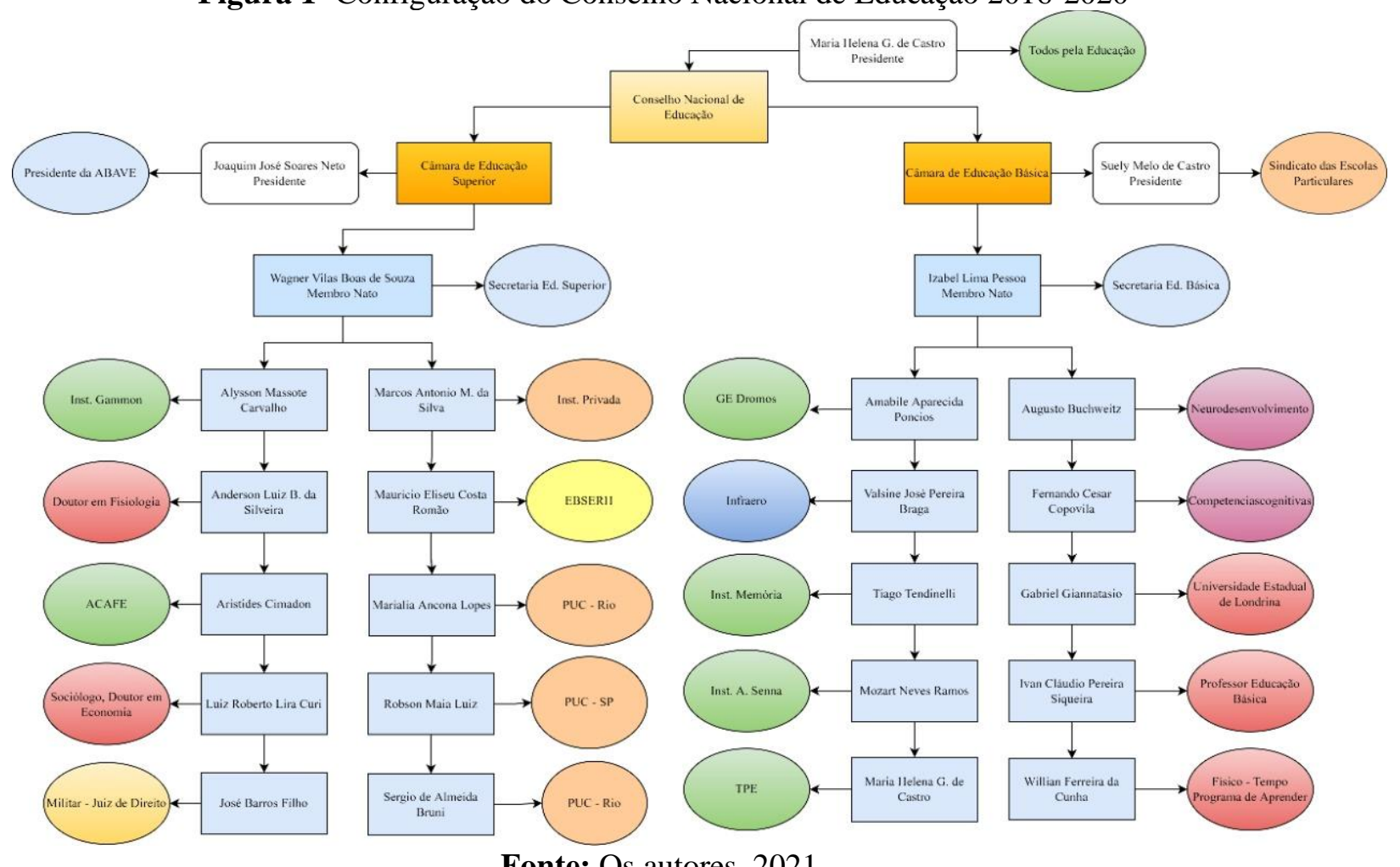

Fonte: Os autores, 2021.

De acordo com a Figura 1, acima, é perceptível, na nova configuração das duas Câmaras de Educação Básica e do Ensino Superior, que a maioria dos seus membros é vinculada a 
agências multilaterais e a organizações não governamentais, privadas ou com gestão tripartite. Podemos inferir que a atual constituição do CNE, a partir da indicação dos novos membros, possibilita a mobilidade de políticas que tentam "capturar e modelar" os conhecimentos que circulam globalmente e importá-los para as políticas nacionais. Para Ball (2014), a mobilidade ocorre por meio das redes de relações sociais com vários tipos de interesse. Essas Redes de Política são compreendidas como um tipo de "social" novo, que envolve modelos específicos de relações sociais, de fluxos e de movimentos. Elas se constituem como comunidades de políticas, geralmente baseadas em concepções partilhadas de problemas sociais e suas soluções. São novas vozes, dentro do discurso da política e, neste caso, dentro do Conselho responsável por emitir pareceres sobre procedimentos e resultados de processos de avaliação da educação superior, educação básica e suas modalidades, além de deliberar sobre diretrizes curriculares propostas pelo Ministério da Educação e acompanhar a execução do Plano Nacional de Educação (PNE).

Não pretendemos, neste texto, abordar as especificidades dessa nova configuração responsável por propor novas diretrizes para a educação do país. A análise das atividades da rede e seus fluxos, compromissos e conexão serão discutidos, detalhadamente, no término da pesquisa que desenvolvemos em outro manuscrito. Ao apresentar o mapa com a configuração do CNE, intencionamos visibilizar as relações complexas dos representantes com empresas, instituições filantrópicas e organizações internacionais, que assumem espaços e oportunidades públicas, a partir do discurso da defesa dos serviços educacionais.

$\mathrm{Na}$ seção seguinte, destacamos as principais alterações no sentido de formação docente instituído pela nova diretriz proposta pelo $\mathrm{CNE}$ e indicamos os distanciamentos e as perspectivas de conhecimento que estão postas e serão responsáveis por estabelecer as aprendizagens essenciais a serem aprendidas e garantidas aos estudantes da educação básica. Tal vinculação denota a compreensão de formação estabelecida, implicitamente, por esse novo documento e conduz a um tipo específico de formação de sujeitos.

\section{3 - AS DIRETRIZES DE FORMAÇÃO INICIAL 2019 - ALGUNS (DES) CAMINHOS}

Nas últimas décadas, o processo de reestruturação produtiva, as alterações na divisão internacional do trabalho e as tentativas de se estabelecer como um importante lócus competitivo para o empresariado, originou, no Brasil, políticas públicas alicerçadas pelos princípios neoliberais, especificamente para a área educacional. Compreendidas como "políticas itinerantes de educação" (Traveling Policies Education) ou de "políticas viajantes" (Ozga \& Jones 2006), essas novas normativas promoveram mudanças no trabalho e na profissão docente, ao constituir uma agenda que recomenda a descentralização dos sistemas educativos, reduz a autonomia das escolas e, de forma mais efetiva, tenta homogeneizar, principalmente, os currículos nacionais.

Freitas (2018, p. 31) assevera que o neoliberalismo considera a educação como responsável por promover uma concepção de sociedade "baseada no livre mercado, cuja 
própria lógica produz o avanço social com qualidade, depurando ineficiência através da concorrência". Com base nessa visão, estabelecem-se as finalidades da educação. Por isso, em diversos países, a introdução da lógica de mercado nas instituições públicas de ensino tem sido a principal ação dos governos para melhorar a "qualidade da educação" o que não seria possível sem o controle do empresariado, visto que tal perspectiva considera a educação pública ineficiente. Impulsionados e pressionados por instituições privadas, fundações filantrópicas e organizações sem fins lucrativos, os governos nacionais têm cedido às pressões desses grandes conglomerados que prometem elevar os índices educacionais estabelecendo os mesmos critérios empresariais como modelo a ser seguido (RODRIGUES e HONORATO, 2020). Diversos autores têm revelado como as fundações filantrópicas vêm atuando ativamente na educação sendo responsáveis diretos pela aprovação de múltiplos dispositivos legais, ao se aproximar de legisladores ou se organizar em redes para alterar as políticas públicas nos níveis nacional e subnacional em diversos países (TARLAU E MOELLER, 2020).

Concordamos com Viseu e Oliveira (2020), ao afirmarem que as ações de intervenção do Estado se configuram, principalmente, em dois planos: avaliação estandardizada e definição da carreira e da avaliação dos professores. No tocante às avaliações em larga escala, dentre outros objetivos, pretendem "certificar" as instituições, principalmente as públicas, que atendem a uma educação considerada minimamente de boa "qualidade". A partir dos resultados obtidos e amplamente divulgados, os pais estarão aptos a "escolher" as "melhores" escolas. A "qualidade" é compreendida a partir de critérios avaliativos externos, constitui-se como mercadoria e passa a ser determinante na seleção e na organização do que deverá ou não ser ensinado, com o fim de atender a competências e a habilidades estabelecidas como prioritárias para os ditames neoliberais.

Essas avaliações também serão responsáveis por normatizar o fazer docente, porque a instituição não será mais responsável por estabelecer, durante a organização de sua proposta curricular, os conhecimentos necessários a partir das especificidades dos sujeitos e seus contextos sociais, econômicos, políticos e culturais. A formação continuada passa a ser entendida como responsável pela reprodução de competências e habilidades previamente orientadas por sequências didáticas homogêneas, direcionadoras do fazer docente.

Compreendemos que os grupos empresariais atuaram efetivamente para aprovar a Base Nacional Comum Curricular para a Educação Básica, que alterou substancialmente os sistemas de ensino e o trabalho do professor, ao determinar o que deve ou não ser ensinado e tentar regular o trabalho docente, a partir do estabelecimento pelo Conselho Nacional de Educação das Diretrizes Curriculares Nacionais para a Formação Inicial de Professores para a Educação Básica, e instituiu a Base Nacional Comum para a Formação Inicial de Professores da Educação Básica (BNC-Formação), através da Resolução CNE/CP Nº 2, de 20 de dezembro de 2019. Uma das principais e profundas mudanças observadas nos dois documentos foi a alteração na educação como um direito público subjetivo (CURY, 2002), para a educação como bem privado que pode ser controlado, através do estabelecimento de normativas curriculares. 
Ressaltamos, porém, que foi no processo de implementação das Diretrizes de 2015 que o Conselho Nacional de Educação (CNE) aprovou a Resolução CNE/CP no 2/2019 e dispõe sobre as novas Diretrizes Curriculares Nacionais para a Formação Inicial de Professores, para a Educação Básica e a Base Nacional Comum para a Formação Inicial de Professores da Educação Básica (BNC-Formação). As Diretrizes de 2015 foram revogadas com muitas críticas do meio acadêmico e das entidades científicas que recomendaram seu arquivamento devido à descaracterização da formação de professores pleiteada anteriormente.

Freitas (2002) enuncia que a Resolução CNE/CP n02/2019 é a expressão de um projeto desprofissionalização que visa legitimar a formação por meio de institutos superiores de educação, relegando as universidades e a produção acadêmica sobre a docência e reduz a formação às expectativas da Base Nacional Comum Curricular (BNCC, 2017).

Na parte inicial da Resolução CNE/CP n ${ }^{\circ}$ 2, de 20 de dezembro de 2019, os legisladores já definem que "as aprendizagens essenciais" que garantam o pleno desenvolvimento do estudante, nos termos do art. 205 da Constituição Federal, reiterado pelo art. $2^{\circ}$ da LDB, "requerem o estabelecimento das pertinentes competências profissionais dos professores". Tal determinação vincula a BNCC - Educação Básica à BNC - Formação Continuada, o que dificulta a inclusão das especificidades dos sujeitos e seus contextos nas propostas escolares e de formação. Vejamos, abaixo, o que disciplina a referida resolução:

Art. $2^{\circ}$ A formação docente pressupõe o desenvolvimento, pelo licenciando, das competências gerais previstas na BNCC-Educação Básica, bem como das aprendizagens essenciais a serem garantidas aos estudantes, quanto aos aspectos intelectual, físico, cultural, social e emocional de sua formação, tendo como perspectiva o desenvolvimento pleno das pessoas, visando à Educação Integral.

Para Taffarel (2019), essa "formação formatada" na lógica do capital, instituida pelo Conselho Nacional de Educação da BNC-Formação (assim como fez a BNCC- Educação Básica) e das competências gerais a serem garantidas aos estudantes e em seu anexo, lista as 10 competências gerais docentes que se contrapõem às proposições encaminhadas de forma veemente e reiterada pelas entidades do campo da Educação que defendem uma política global de formação de professores "que contemple a formação inicial e continuada, as condições de trabalho, o salário digno e a carreira, sintonizada com as demandas do processo de trabalho pedagógico, e as demandas formativas da infância, da juventude e dos adultos"(p.6).

O debate e as críticas ao modelo estabelecido para a formação inicial e continuada de professores, prevista na BNCC-Educação Básica têm mobilizado diversos questionamentos de pesquisadores das mais várias áreas do conhecimento, especialmente dos que estudam as políticas curriculares. Destacamos, inclusive, que as tensões epistemológicas presentes entre esses estudiosos foram desconsideradas, devido à necessidade de uma luta coletiva maior em defesa da educação pública, socialmente referenciada e de boa qualidade, que se encontrava sob forte ameaça. Na seção seguinte, refletimos sobre as (des) anunciações das entidades, por 
meio da análise das notas elaboradas e divulgadas em sites e em redes sociais, e mostramos que os conhecimentos foram rejeitados e defendidos a partir das diretrizes estabelecidas.

\section{4 - AS ANUNCIAÇÕES DAS ENTIDADES CIENTÍFICAS: QUE COMPREENSÕES DE CONHECIMENTO REJEITAM?}

A partir de 2019, as entidades científicas e os fóruns de licenciaturas intensificaram suas lutas em contraposição às políticas de formação docente que foram se ampliando a partir do golpe de 2016. Esses movimentos se articularam para desenvolver ações mais efetivas no CNE/MEC, como ANFOPE, ANPAE, ANPED, CEDES, ABdC e Forumdir. Nesse percurso analítico documental, selecionamos: a) nota da ANPED - Uma Formação Formatada - de 06 de maio de 2019, que consiste na posição da ANPED sobre o texto referência - Diretrizes Curriculares Nacionais e Base Comum para a formação Inicial e Continuada de Professores da Educação Básica e que antecede a aprovação da Res. 20/2019; b) o Manifesto em Defesa da Formação de Professores, de dezembro de 2018, produzido pela Associação Nacional pela Formação dos Profissionais da Educação (ANFOPE) e o Fórum Nacional de Diretores de Faculdades/Centros/ Departamentos de Educação ou Equivalentes das Universidades Públicas Brasileiras - FORUMDIR; c) O manifesto da ANPED e entidades signatárias, de novembro de 2020, intitulado 'Contra a Desqualificação da Formação dos Professores da Educação Básica’, em repúdio à homologação da Resolução CNE/CP nº 1, de 27/10/2020, que define as Diretrizes Curriculares Nacionais para a Formação Continuada de Professores da Educação Básica e institui a Base Nacional Comum para a Formação Continuada de Professores da Educação Básica (BNC-Formação Continuada).

Os três documentos referidos foram selecionados porque abarcam as importantes reivindicações políticas de formação e, sobretudo, contemplam importantes entidades signatárias que se debruçam sobre as políticas educacionais brasileiras e agregam grupos de trabalho que representam as pesquisas e os pesquisadores brasileiros no campo educacional. Apesar de as formulações teórico-epistemológicas que atravessam os documentos não serem homogêneas, neste estudo, detemo-nos nas pautas comuns sobre o que rejeitam essas entidades, em termos de perfil formativo da docência. 
Figura 2: Princípios defendidos pelas entidades e relação com os artigos da DCN 02/2019

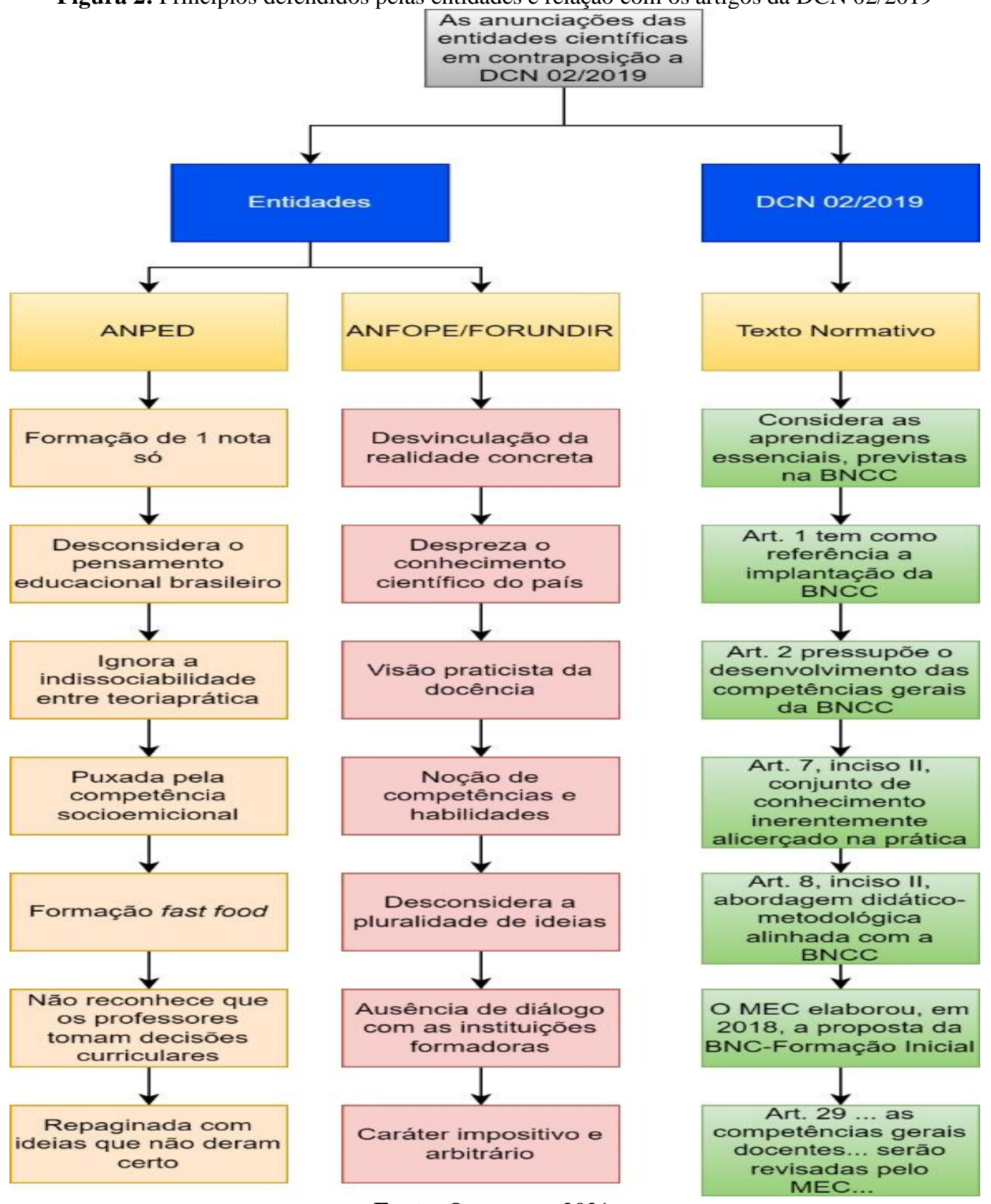

Fonte: Os autores, 2021. 
A Resolução CNE/CP $n^{\circ}$ 2/2019, que institui uma Base Nacional Comum para a Formação Inicial de Professoras e Professores da Educação Básica, em substituição à Resolução CNE/CP N 2/2015, também impõe mudanças significativas na estrutura do Curso de Pedagogia, uma vez que a formação para Educação Infantil, Ensino Fundamental e Gestão Escolar será oferecida como uma habilitação independente. A forma autoritária em torno da política curricular de formação docente fica explícita, não só no que concerne a uma formação teórica sólida dos profissionais, porque também se revela como um ataque nefasto à autonomia das universidades preconizada pela Constituição Federal de 1988 e, por conseguinte, seus colegiados e núcleos docentes estruturantes.

Tratamos, aqui, das rejeições das entidades à formação pleiteada pela pelo texto de referência que antecedeu a Resolução 02/2019, no sentido de anunciar, a partir de uma compreensão freireana, que toda denúncia também traz, em seu fluxo, um anúncio. As entidades se manifestam em torno do texto de referência que subsidiou a produção da referida resolução.

A ANPED, em sua nota intitulada 'Uma Formação Formada', de 05 de maio de 2019, anuncia que é preciso promover uma formação sistematizada pelos contextos e os cotidianos acadêmicos plurais. As críticas são pontuadas e evidenciam os retrocessos na formação de professores. São nove os motivos que contrariam a pluralidade da associação:

1. Uma formação de professores de "uma nota só";

2. Uma proposta de formação que desconsidera o pensamento educacional brasileiro;

3. Uma proposta de formação docente que ignora a indissociabilidade teoriaprática;

4. Uma proposta de formação 'puxada' pela competência socioemocional;

5. Um texto higiênico em relação à condição social do licenciando;

6. Uma formação que repagina ideias que não deram certo;

7. Uma proposta que estimula uma formação fast food;

8. Uma formação de professores com pouco recurso;

9. Uma formação que não reconhece que o professor toma decisões curriculares.

No motivo inicial, a formação caracterizada como de "uma nota só", refere-se ao fato de o parâmetro de referencial único ser a BNCC(2017), que se articula aos argumentos na mesma direção da nota da ANFOPE/Forumdir (2018) e vai reafirmar a desconexão da base e a realidade dos contextos diversos que estrutura os "brasis". Na nota da ANPED que se antecipava à aprovação da Res. 02/2019, a ideia de "uma nota só" faz referência ao samba musicado por Tom Jobim com a letra de Newton Mendonça e anuncia o batuque da política: Eis aqui este sambinha feito numa nota só - Outras notas vão entrar, mas a base é uma só.

Essa obsessão pela padronização ancora-se às agendas multilaterais e, em âmbito internacional, tem movimentado as perspectivas de formação para sustentar a economia global. O Movimento de Reforma Educacional Global (GERM) traz uns referentes importantes. Pasi Sahlberg (2012) analisou esse movimento e descreve um panorama histórico o qual aponta que, desde os anos de 1980, um aporte de tecnologias políticas foi 
adotado de forma ortodoxa do que deveria ser a reforma global de educação sustentada por uma ideia de qualidade em que o princípio de padronização aparece como necessidade. Nesse contexto, a padronização tem foco nos estudantes, mas também na prescrição curricular. Esse modo de constituir uma política de formação é negado pela ANPED (2019), quando trata sobre a minuta da Resolução 02/2019: "Um discurso pragmatista da educação e que insiste em sua determinação pelo desenvolvimento econômico sustentado pela ideia do direito à aprendizagem individual em detrimento de um projeto coletivo de educação" e ainda o que nessa análise, consideramos mais grave: afirmar a desigualdade como um "registro intrinsecamente pedagógico" (LOPES, 2018, p. 25).

A primeira rejeição nas notas das entidades refere-se a essa homogeneização curricular em sentido ampliado, que esvazia a escola e, por conseguinte, o sentido de público que traduz a formação dentro de um roteiro pragmático e utilitário. A autonomia, entendida em sua dimensão relacional, é descaracterizada no processo de formação, sobretudo quando pensamos na docência como um movimento de tomada de decisão e empreendimento político dado à sua natureza humana e existencial. A competência atravessa e se impõe como essencialidade e investimento histórico aquém da perspectiva de pensar na pluralidade e na diferença.

Muitos questionamentos são feitos, ao longo das notas, sobre a desconsideração e a falta de reconhecimento dos elaboradores da política, o acúmulo de estudos e de pesquisas das universidades, das instituições formativas e dos centros de pesquisas sobre a escola, o currículo, a formação e a avaliação da educação do país. No texto da Resolução 02/2019, consta a vinculação direta dos conhecimentos pedagógicos a serem ensinados com as competências estabelecidas pela BNCC. Esses conhecimentos epistemológicos foram invisibilizados porque não se alinhavam às concepções implícitas e explícitas que esvaziaram e desqualificaram a formação de professores ao restringir a conceitos mercadológicos e empresariais suas bases pedagógicas.

\section{5 - EM TORNO DA FORMAÇÃO CONTINUADA E DO PROSSEGUIMENTO DAS LUTAS DAS ENTIDADES CIENTÍFICAS}

O manifesto em repúdio à homologação da Resolução CNE/CP n ${ }^{\circ}$ 1, de 27/10/2020, que define as Diretrizes Curriculares Nacionais para a Formação Continuada de Professores da Educação Básica e institui a Base Nacional Comum para a Formação Continuada de Professores da Educação Básica (BNC-Formação Continuada), foi divulgado pela ANPED em 05 de novembro de 2020 e repudiava, junto com mais 16 entidades científicas, tal aprovação. $O$ anúncio retoma as discussões importantes já empenhadas nos retrocessos políticos da Resolução 02/2019 que trata da Formação Inicial.

A ANPED afirma que essa política de formação atua no desmonte e na desqualificação de professores no Brasil e que, em maio de 2021, a entidade já havia se manifestado ante a minuta de resolução listando os argumentos sobre a normativa que, em sua perspectiva, "acentuaria os processos de desvalorização e precarização da formação dos profissionais do Magistério da 
educação básica”. Além disso, assim como foi com a Resolução 02/2019, que trata da Formação Inicial, havia falta de diálogo com "as instituições universitárias, as associações científicas do campo educacional e as entidades representativas dos professores, em uma prática impositiva e autoritária" (ANPED, 2020).

A ANPED evidenciou a crise sanitária e econômica e o anacronismo da Resolução de 2020, ressaltou a impropriedade e a falta de sensibilidade política, ante o número de mortos do país e a ausência de demandas do poder público para socorrer as vítimas do vírus e do desemprego e retratou a omissão do Ministério da Educação (MEC) durante a pandemia, sobretudo as condições materiais de acesso dos estudantes, dos professores e da comunidade ao ensino remoto. A falta de debates e de consultas, agravada por um contexto de emergência de saúde pública, é um motivo basilar do repúdio da entidade e das que subscrevem o manifesto.

No manifesto, ressaltaram que o Ministério da Educação e o CNE se mostraram indiferentes ao conhecimento produzido na Academia e "as manifestações fundamentadas das associações científicas, dos pesquisadores e das universidades, que denunciam a falácia da proposta e os interesses privatistas embutidos, desde a apresentação da minuta do parecer”. (ANPED, 2020).

Abaixo, apresentamos um quadro-síntese com as principais preconizações de formação continuada pleiteadas pela Resolução CNE/CP nº 1, de 27/10/2020, que define as Diretrizes Curriculares Nacionais para a Formação Continuada de Professores da Educação Básica e institui a Base Nacional Comum para a Formação Continuada de Professores da Educação Básica (BNC-Formação Continuada), e destacamos, em linhas gerais, o que a ANPED e as entidades signatárias do Manifesto de 2020 rejeitaram como percurso no mesmo âmbito formativo.

Quadro 1 - Demonstrativo das disputas políticas pelo currículo da Formação Continuada Resolução CNE/CP nº 1, de 27/10/2020 - Preconizações legais e rejeições históricas das associações científicas

\begin{tabular}{|c|c|}
\hline $\begin{array}{l}\text { O QUE PRECONIZAM? } \\
\text { Resolução CNE/CP no 1, de 27/10/2020, que } \\
\text { define as Diretrizes Curriculares Nacionais para a } \\
\text { Formação Continuada de Professores da Educação } \\
\text { Básica e institui a Base Nacional Comum para a } \\
\text { Formação Continuada de Professores da Educação } \\
\text { Básica (BNC-Formação Continuada). }\end{array}$ & $\begin{array}{l}\text { O QUE REJEITAM? } \\
\text { ANPED, ANFOPE/Forumdir e signatárias }\end{array}$ \\
\hline $\begin{array}{l}1 \text { - Referência de Formação BNCC (CNE/CP n } \\
02 / 2017 \text { e CNE/CP } n^{0} \quad 04 / 2018\end{array}$ & $\begin{array}{l}1 \text { - Modelo centrado em competências e uma } \\
\text { concepção esvaziada de currículo que sonega } \\
\text { a pluralidade e fere o princípio da gestão } \\
\text { democrática e da liberdade de ensinar e } \\
\text { aprender. }\end{array}$ \\
\hline
\end{tabular}




\begin{tabular}{|c|c|}
\hline $\begin{array}{l}2-\quad \text { Formação inicial e continuada, } \\
\text { complementaridade e correção da formação inicial }\end{array}$ & $\begin{array}{l}2 \text { - Fragmentação da formação - Essa } \\
\text { formulação rompe com a perspectiva de } \\
\text { organicidade e com a articulação necessária } \\
\text { prevista na Resolução CNE/CP n } 2 / 2015 \text {. }\end{array}$ \\
\hline $\begin{array}{l}3 \text { - Foco nos princípios de competências gerais da } \\
\text { BNCC }\end{array}$ & $\begin{array}{l}3 \text { - Conhecimento reduzido às competências- } \\
\text { negação da pedagógica na unidade teoria e } \\
\text { prática }\end{array}$ \\
\hline $\begin{array}{l}4 \text { - Meritocrática e empreendedora de formação. } \\
\text { Responsabilização individual de sucesso e fracasso }\end{array}$ & $\begin{array}{l}4 \text { - Esvaziamento da formação como direito a } \\
\text { ser garantido pelas políticas públicas. }\end{array}$ \\
\hline $\begin{array}{l}5 \text { - Foco no conhecimento pedagógico do } \\
\text { conteúdo; uso de metodologias de aprendizagem }\end{array}$ & $\begin{array}{l}5 \text { - O caráter padronizador e o controle da } \\
\text { formação continuada, pois, focam no } \\
\text { conhecimento do conteúdo, nesse caso, a } \\
\text { BNCC e nas metodologias ativas }\end{array}$ \\
\hline $\begin{array}{l}6 \text { - A BNC-FC intenciona articular a ideia de } \\
\text { competência profissional docente ao atendimento } \\
\text { dos objetivos de aprendizagem prescritos pela } \\
\text { BNCC e aos resultados das avaliações de larga } \\
\text { escala. }\end{array}$ & $\begin{array}{l}6 \text { - Redução do direito à educação ao direito à } \\
\text { aprendizagem centrando-se, portanto, em } \\
\text { resultados em detrimento de uma perspectiva } \\
\text { processual e formativa }\end{array}$ \\
\hline $\begin{array}{l}7-\text { Formação sem anúncio de vínculo } \\
\text { universidade-escola }\end{array}$ & $\begin{array}{l}7 \text { - Esvaziamento da relação entre a } \\
\text { universidade e a escola nas proposições de } \\
\text { ações formativas, anulando o acúmulo } \\
\text { histórico de experiências no âmbito da Rede } \\
\text { Nacional de Formação Continuada - } \\
\text { RENAFOR, que não fora legalmente extinta. }\end{array}$ \\
\hline
\end{tabular}




\begin{tabular}{|c|c|}
\hline $\begin{array}{l}8 \text { - Proposição de formação sem referentes } \\
\text { importantes das pesquisas produzidas no Brasil }\end{array}$ & $\begin{array}{l}8 \text { - Ausência de diálogo com as pesquisas } \\
\text { sobre formação de professores produzidas no } \\
\text { Brasil nas últimas décadas, em especial, as } \\
\text { que têm como objeto de investigação a } \\
\text { formação continuada e o desenvolvimento } \\
\text { profissional docente. }\end{array}$ \\
\hline $\begin{array}{l}9 \text { - Alinhamento à agenda global de políticas } \\
\text { educacionais neoliberais }\end{array}$ & $\begin{array}{l}9 \text { - Consolidação de reformas e programas } \\
\text { escolares calcados na relação de baixo custo e } \\
\text { performatividade, que favorece a privatização } \\
\text { da formação continuada. }\end{array}$ \\
\hline $\begin{array}{l}10 \text { - Uma formação fora da compreensão do } \\
\text { Sistema Nacional de Educação } \\
\text {. }\end{array}$ & $\begin{array}{l}10 \text { - Secundarização do esforço para instituir } \\
\text { o Sistema Nacional de Educação - garantia de } \\
\text { efetiva formação inicial articulada à formação } \\
\text { continuada pelos entes } \\
\text { federados e seus sistemas. }\end{array}$ \\
\hline
\end{tabular}

Fonte: Os autores, 2021

A partir da síntese estruturada no quadro acima sobre o Manifesto da ANPED(2020) e as demais entidades signatárias, é possível perceber a manutenção de ordenamentos comuns em torno da formação docente, se tomarmos os referentes textuais que ensejaram a formação inicial e foram contestadas pelos dois textos já sinalizados neste estudo: a ANPED (2019) e a ANFOPE/Forumdir (2018). A BNCC(2018) é o referente primordial do desenho formativo para a docência com o seu arsenal de habilidades e competências.

A noção de formação continuada ficou reduzida como outra etapa do processo de formação de professores, e não, entendida como um continuum curricular. Configurou-se como um salto e um complemento formativo, enquanto se afastou da ideia de política de Estado, direito e condição "ontológica e epistemológica" profissional de professores. Corrompeu a condição humana e existencial da docência e compactuou com a "nota só" já evidenciada na política de formação inicial.

O manifesto (ANPED, 2020) se encerra clamando pela defesa da formação e da valorização dos profissionais de Educação, que não se encerra na docência, e, sobretudo, por 
uma educação pública, pela vida e pela democracia. Partindo dos argumentos postos ao longo do documento, solicita:

1) A revogação imediata da Resolução $\mathrm{CNE} / \mathrm{CP} \mathrm{n}^{0}$ 02/2019 e da Resolução

$\mathrm{CNE} / \mathrm{CP} \mathrm{n}^{0}$ 01/2020 e seus respectivos Pareceres;

2) A implementação imediata da Resolução CNE/CP n ${ }^{0}$ 02/2015; e

3) O restabelecimento do debate público e republicano com as instituições

formadoras de professores, pesquisadores do campo da formação de professores

e representantes de movimentos educacionais, sociais e sindicais.

Os modos de regular a docência também ficam bem configurados no modelo de formação continuada. Ao pedir revogação imediata das Resoluções CNE/CP n ${ }^{0}$ 02/2019 $\mathrm{CNE} / \mathrm{CP} \mathrm{n}^{0}$ 01/2020 e seus respectivos Pareceres, a ANPED e as demais entidades rejeitam as feições meritocráticas e de responsabilização gerencialista de formação docente, que Freitas (2012, p. 383) denomina de neotecnicistas, referendadas em três elementos: responsabilização, meritocracia e privatização. Assim, entendemos que as expectativas de aprendizagem docente são orientadas por concepções que renovam a Psicologia behaviorista e fortalecidas pela Econometria e pelas Ciências da Informação e de Sistemas, tomadas como referenciais básicos de sustentação - a panaceia das competências.

\section{Considerações finais}

As entidades científicas desempenham um papel preponderante no processo de disputa e de reconstrução/ressignificação de políticas educativas. No caso das políticas curriculares para a formação docente, percebemos a intensificação das lutas, sobretudo nos processos que antecedem as duas Resoluções (formação inicial e formação continuada). As entidades se manifestaram oficialmente no processo de produção dos textos políticos e não foram respeitadas em suas reivindicações pelo CNE. Além de apontar ausências teórico-conceituais e socioculturais nas resoluções, destacam que as normativas ferem o princípio da ordem democrática com a coisa pública. Em plena crise sanitária, política e econômica, esses documentos seguiram o fluxo de produção política, sem que, principalmente, os docentes da educação básica tivessem a oportunidade de debater e de escutar.

À guisa de conclusão "temporária" dessa análise documental, veja-se uma matéria jornalística da Gazetaweb, publicada em 15 de maio de 2020, que traz o depoimento de uma criança que pode ser ilustrativo diante dos movimentos de resistência contra a forma e os processos de elaboração da Resolução 02/2019 e 01/2020. Ela enviou um áudio para sua professora, comunicando que não conseguia fazer as atividades: "sem você, professora, eu não consigo aprender bem. A mãe não é igual a você, você tem as manias de 'prof', a minha mãe não tem, ela trabalha num restaurante, ela só tem as manias de fazer comida". Na fala infante, quais são as manias de "prof"? Como elas podem ser contempladas com um fazer itinerante e democrático nas políticas curriculares de formação? A criança afirma uma profissionalidade não evidenciada nas políticas de formação que descaracterizam a realidade, em favor de uma normatização técnica de habilidades e competências. Se a docência é 
caracterizada por suas "manias", há que afirmá-las de forma democrática e em processo de negociação simbiótica de produção dos seres/saberes.

Assim, as entidades científicas evidenciadas nesse recorte de análise histórica e documental (ANPED, ANFOPE, FORUMDIR) e demais signatárias impulsionam, de forma sistematizada, perspectivas epistêmicas plurais de formação, reivindicam processos democráticos de participação e, sobretudo, exigem respeito às produções acadêmicas e ao trabalho das associações acumulado historicamente.

Os movimentos de luta das entidades começaram a impulsionar outros rumos na resistência propositiva e fortaleceram a ampliação do número de fóruns de discussão da formação docente. $\mathrm{O}$ adiamento da adequação dos cursos de formação inicial terá mais um ano para se articular às diretrizes de 2019. O prazo que estaria se encerrando em 2021 foi ampliado para o final de 2022, já aprovado pelo Conselho Nacional de Educação (CNE). Assim, criou-se a expectativa de que as políticas curriculares de formação de professores podem ser refeitas e reposicionadas politicamente. Almejamos ampliar a escala política desse "samba de uma nota só", pois um currículo de formação docente pode, inclusive, transbordar o ré, mi, fá, sol, lá, si, dó e impulsionar outras sonoridades e ritmos na produção do conhecimento.

\section{Referências}

AGUIAR, M. A. S., \& DOURADO, L. F. BNCC e formação de professores: concepções, tensões, atores e estratégias. Revista Retratos da Escola, Brasília, 13(25), 33-37, 2019. Disponível em: http://retratosdaescola.emnuvens.com.br/rde/article/view/990/pdf. Acesso em: 29 de novembro de 2021.

ANPED - ASSOCIAÇÃO NACIONAL DE PÓS-GRADUAÇÃO E PESQUISA EM EDUCAÇÃO. Uma formação formatada: posição da Anped sobre o "Texto Referência - Diretrizes Curriculares Nacionais e Base Nacional Comum para a Formação Inicial e Continuada de Professores da Educação Básica". Disponível em: http://www.anped.org.br/news/posicao-da-anped-sobre-texto-referencia-dcn-e-bncc-paraformacao-inicial-e-continuada-de Maio de 2019. Acesso em: 20 de agosto de 2021.

ANPED - ASSOCIAÇÃO NACIONAL DE PÓS-GRADUAÇÃO E PESQUISA EM EDUCAÇÃ̃ Manifesto em repúdio à homologação da Resolução $C N E / C P n^{0} 1$, de 27/10/2020, que define as Diretrizes Curriculares Nacionais para a Formação Continuada de Professores da Educação Básica e institui a Base Nacional Comum para a Formação Continuada de Professores da Educação Básica (BNC-Formação Continuada). Novembro de 2020. Acesso em agosto de 2021.

ASSOCIAÇÃO NACIONAL PELA FORMAÇÃO DOS PROFISSIONAIS DA EDUCAÇÃO (ANFOPE) E O FÓRUM NACIONAL DE DIRETORES DE FACULDADES/CENTROS/ DEPARTAMENTOS DE EDUCAÇÃO OU EQUIVALENTES DAS UNIVERSIDADES PÚBLICAS BRASILEIRAS FORUMDIR. Manifesto em defesa da Formação de Professores. Disponível em: http://www.anfope.org.br/wp-content/uploads/2020/03/MANIFESTO-DEFESA-

FORMA\%C3\%87\%C3\%83O_PROFESSORES-Anfope-Forumdir-14Dez2018.pdf, 14 de dezembro de 2018. Acesso em 10 de agosto de 2021.

ARROYO, Miguel Gonzales. Outro olhar sobre os educandos. In: ARROYO, Miguel González. Outros sujeitos, outras pedagogias. Petrópolis, RJ: Vozes, 2012. 336 p.

BALL, S. J. Educação Global S. A.: novas redes políticas e o imaginário neoliberal. Tradução de Janete 
Bridon. Ponta Grossa: UEPG, 2014.

BRASIL. Conselho Nacional de Educação. Define as Diretrizes Curriculares Nacionais para a formação inicial em nível superior (cursos de licenciatura, cursos de formação pedagógica para graduados e cursos de segunda licenciatura) e para a formação continuada. Resolução CNE/CP n. 2/2015, de $1^{\circ}$ de julho de 2015. Brasília, Diário Oficial [da] República Federativa do Brasil, seção 1, n. 124, p. 8-12, 02 de jul. de 2015.

BRASIL. Ministério da Educação. Base Nacional Comum Curricular: Educação Infantil e Ensino Fundamental. Brasília: MEC/Secretaria de Educação Básica, 2017.

BRASIL. Ministério da Educação. Base Nacional Comum Curricular. Brasília, 2018.

BRASIL. Conselho Nacional de Educação. Define as Diretrizes Curriculares Nacionais para a Formação Inicial de Professores para a Educação Básica e institui a Base Nacional Comum para a Formação Inicial de Professores da Educação Básica (BNC-Formação). Resolução nº. 2/2019, de 20 de dezembro de 2019. Diário Oficial [da] República Federativa do Brasil, seção 1, n. 28, p. 115-119, 10 de fev. de 2020.

BRASIL. Lei de 15 de outubro de 1827. In: LIMA, Nestor dos Santos. Um século de ensino primário. Natal: Typografia d'A República, 1927.

CNE (Conselho Nacional de Educação) (2019). 3 $3^{a}$ versão do parecer (Atualizada em 18/09/19) Assunto: Diretrizes Curriculares Nacionais e Base Nacional Comum para a Formação Inicial e Continuada de Professores da Educação Básica. Disponível em:http://portal.mec.gov.br/index.php?option=com_docman\&view=download\&alias=124721 textoreferencia-formacao-de-professores\&category_slug=setembro-2019\&Itemid=30192 - Acesso julho 2021.

CURY, C. R. J. A Educação Básica no Brasil. Educ. Soc., v. 23, n. 80, p. 168-200, set., 2002.

DOURADO, L. F. Diretrizes Curriculares Nacionais para a Formação Inicial e Continuada dos Profissionais do Magistério da Educação Básica: concepções e desafios. Educação \& Sociedade, Campinas, v. 36, nº 131, p. 299-324, abr.-jun., 2015.

DUARTE, N. O currículo em tempos de obscurantismo beligerante. Revista Espaço do Currículo (online), João Pessoa, v. 11, n. 2, p. 139-145, mai/ago. 2018 . Disponível em: https://periodicos.ufpb.br/ojs2/index.php/rec/issue/view/2121. Acesso setembro, 2021.

FREIRE, Paulo. Pedagogia do Oprimido. 41. ed. Rio de Janeiro: Paz e terra, 2005.

FREITAS, H. Formação de professores no Brasil: 10 anos de embate entre projetos de formação. Educação \& Sociedade, Campinas, v. 23, n. 80, p. 136-167, set. 2002.

FREITAS, L. C. Os reformadores empresariais da educação: da desmoralização do magistério à destruição do sistema público de educação. Revista Educação e Sociedade. Campinas, v. 33, n. 119, p. 379-404, abr.jun.2012.

FREITAS, L. C. A reforma empresarial da educação: nova direita, velhas ideias. 1. ed. São Paulo: Expressão Popular, 2018.

LOPES, A. C. Apostando na produção contextual do currículo, In: AGUIAR, M. A.; DOURADO, L. F. A BNCC na contramão do PNE 2014 - 2024: avaliação e perspectivas. Recife: ANPAE, 2018. p. 23-27.

MACEDO, E. "A base é a base". E o currículo o que é? In: AGUIAR, M. A. S.; DOURADO, L. F. A BNCC na contramão do PNE 2014-2024: avaliação e perspectivas. [Livro Eletrônico]. Recife: ANPAE, p. 28-33, 2018.

MOREIRA, Antônio Flávio Barbosa. Multiculturalismo, currículo e formação de professores. Anais do IX Endipe, Águas de Lindóia, SP, 1998.

RODRIGUES, A. C. S.; HONORATO, R. F. S. Redes de política de educação integral da Paraíba: fluxos e influências neoconservadoras e neoliberais. Roteiro, v. 45, p. 1-32, 10 jun. 2020.

SAHLBERG, P. Finnish lessons: what can the world learn from educational change in Finland? New York: Teachers College Press, 2012. 
OZGA, J., \& JONES, R. (2006). Travelling and embedded policy: the case of knowledge transfer. Journal of Education Policy, 21(1), 1-17. doi: 10.1080/02680930500391462

TARLAU, R.; MOELLER, K. O consenso por filantropia: como uma fundação privada estabeleceu a BNCC no Brasil. Currículo sem fronteiras. V.20.n.2, p.553-603, maio/ago.2020

VISEU, S.; OLIVEIRA, D. A. Políticas educativas e mudanças na profissão docente. Sisyphus - Revista de Educação. February 28, 2020. DOI: https://doi.org/10.25749/sis.19427.

\section{Correspondência}

Ana Cláudia Silva Rodrigues: Pedagoga, mestre e doutora em Educação pela Universidade Federal da Paraíba. Professora do Departamento de Fundamentação da Educação, do Centro de Educação da Universidade Federal da Paraíba. Credenciada no Programa de pós-graduação em Educação, linha Política Educacionais, CE/UFPB. Vice-líder do Grupo de Estudos e Pesquisas em Políticas Curriculares (GEPPC) e membro do grupo Currículo e Práticas Educativas (GPESC).

E-mail: anaclaudia@ce.ufpb.br

Ângela Cristina Alves Albino: Professora da Universidade Federal da Paraíba - UFPB. Lider do Grupo de Estudos e Pesquisas em Políticas Curriculares - GEPPC. Editora da Revista Espaço do Currículo. Doutora em Educação, na linha de Políticas Educacionais (UFPB). Tem mestrado em Educação pela Universidade Federal da Paraíba (UFPB) (2010) e Mestrado Interdisciplinar em Ciências Da Sociedade, pela Universidade Estadual da Paraíba (2006). Especialista em Formação do Educador (UEPB). Graduada em Pedagogia com tempo e vida como Professora da Educação Básica.

E-mail: angela.educ@gmail.com

Rafael Ferreira de Souza Honorato: Doutorando e Mestre pelo Programa de Pós-Graduação em Educação (PPGE) da Universidade Federal da Paraíba (UFPB). Membro do Grupo de Estudos e Pesquisas em Políticas Curriculares (GEPPC).

E-mail: rafaelhono@gmail.com

Texto publicado em Currículo sem Fronteiras com autorização dos autores. 